\title{
Implementation of DART and DESI Ionization on a Fieldable Mass Spectrometer
}

\author{
J. Mitchell Wells, Michael J. Roth, Adam D. Keil, \\ John W. Grossenbacher, Dina R. Justes, Garth E. Patterson, and \\ Dennis J. Barket Jr \\ Griffin Analytical Technologies LLC, West Lafayette, Indiana, USA
}

\begin{abstract}
A recently developed prototype mobile laboratory mass spectrometer, incorporating an atmospheric pressure ionization (API) interface, is described. This system takes advantage of the small size, lower voltage requirements, and tandem MS abilities of the cylindrical ion trap mass analyzer. The prototype API MS uses small, low-power pumps to fit into a $0.1-\mathrm{m}^{3}$ self-contained package weighing $<45 \mathrm{~kg}$. This instrument has been adapted to allow rapid interfacing to electrospray ionization, desorption electrospray ionization, and direct analysis in real-time sources. Initial data indicate that these techniques provide rapid detection and identification of compounds for quality control, homeland security, and forensic applications. In addition, this instrument is self-contained and compact, making it ideally extensible to mobile laboratory and field analyses. Initial MS and MS/MS data for analyses of drugs, food, and explosives are presented herein. (J Am Soc Mass Spectrom 2008, 19, 1419-1424) (C 2008 American Society for Mass Spectrometry
\end{abstract}

$\mathrm{O}$ ver the past 15 years, efforts toward implementing mass spectrometry (MS) in the field have steadily grown with particular focus on environmental, forensic, defense, and security applications $[1,2]$. Many of the previously developed fieldable MS instruments use gas chromatography (GC-MS) because of the high degree of confidence obtained using GC retention times and electron ionization (EI) mass spectral matching [3-6]. The specificity of GC-MS comes at the expense of time, with individual analyses often taking in excess of $10 \mathrm{~min}$ (not including sample preparation). Reducing the amount of time required for chemical identification requires separation-free MS. In the absence of chromatography, tandem MS (MS/MS) improves confidence for the identification of individual components in mixtures [7]. With spectral acquisition rates $>1 \mathrm{~Hz}$, atmospheric pressure ionization (API) techniques such as electrospray ionization (ESI), desorption electrospray (DESI), and direct analysis in real time (DART), a fieldable API MS system capable of MS/MS is of high value to environmental, forensic, defense, and force protection agencies. There have been few attempts to construct fieldable MS instruments with an API interface to date [8-11] because of the difficulty of displacing the gas load of the atmospheric inlet.

The cylindrical ion trap (CIT)-a simplified geometry of the hyperbolic quadrupole ion trap capable of

Address reprint requests to Dr. Mitch Wells, Griffin Analytical Technologies, LLC, R\&D, 3000 Kent Avenue, West Lafayette, IN 47906, USA. E-mail: mitch.wells@icxt.com performing $\mathrm{MS}^{n}$ analyses-has been shown to be amenable to miniaturization [12-14] while maintaining benchtop-quality performance characteristics. The miniaturized CIT enables a smaller vacuum system with smaller pumps that consume less power, providing a fieldable instrument. Although GC-MS instruments currently dominate the portable mass spectrometry industry, estimates indicate that the confidence for molecule identification by MS/MS is about that provided with GC-MS (when combining MS information with retention time) [15]. The MS/MS-capable CITbased instrument enables chromatography-free analysis for high confidence in situ molecule identification with 100-fold faster analysis times than standard GC-MS analyses.

Atmospheric pressure desorption ionization techniques, including DESI and DART, are capable of generating ions of diverse chemical nature directly from solid surfaces for MS/MS analysis [10, 16-30]. In forensic $[26,31]$, security $[19,32]$, and quality control applications [17, 27], desorption techniques provide actionable chemical information through rapid, definitive analyses. DESI and DART provide the ability to analyze chemicals of wide-ranging volatilities by simply positioning a surface near the sampling inlet of an APIequipped mass spectrometer $[25,33]$. Various reports present data from samples collected in the field and analyzed by DESI and DART in the laboratory [21, 31, 34-36]. These studies illustrate the potential utility of DESI and DART in the field for analysis of samples immediately upon collection. 

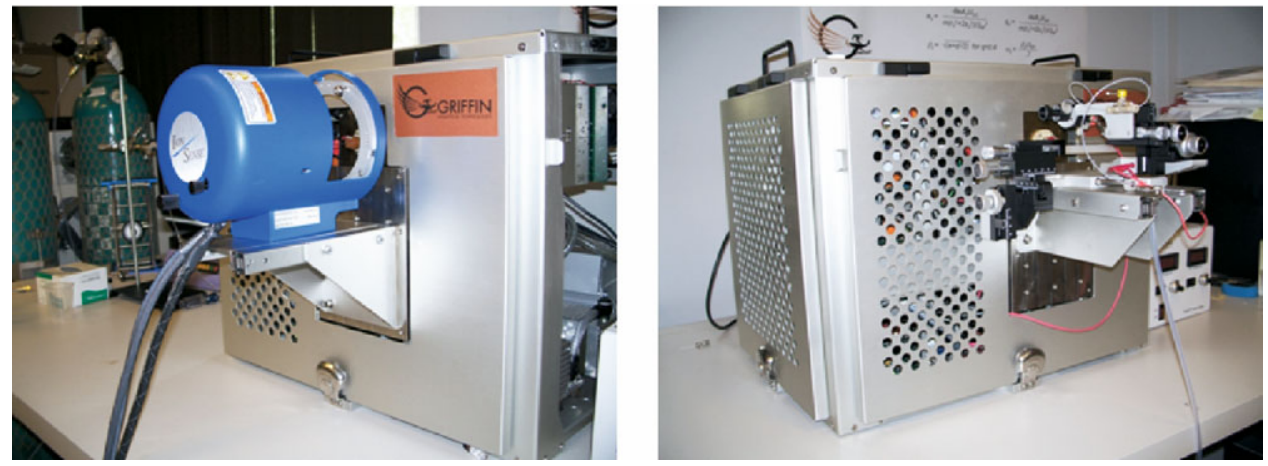

Figure 1. IonSense DART (left) and Prosolia DESI (right) sources installed on the Griffin API prototype instrument.

A prototype fieldable API MS was developed to harness the potential of API and desorption-API techniques for analysis in nonlaboratory environments. The prototype API MS takes advantage of a compact vacuum system and smaller pumps to fit into a $0.1-\mathrm{m}^{3}$ box and weighs $<45 \mathrm{~kg}$. This instrument is capable of tandem MS analyses because of the CIT mass analyzer and gives results similar to those generated using benchtop API 3D quadrupole ion trap instruments. Ions have been generated using ESI, DESI, and DART for analysis of a wide range of molecules from over-thecounter drugs to explosives. Figure 1 shows the prototype instrument with commercial sources for DESI and DART installed.

\section{Experimental}

\section{Materials}

Explosives were purchased from AccuStandard, Inc. (New Haven, CT, USA) at concentrations of $100 \mu \mathrm{g} /$ $\mathrm{mL}$; drug standards were purchased from Supelco (St. Louis, MO, USA); and ibuprofen tablets $\left(\mathrm{Advil}^{\circledR}\right)$, Sharpie ${ }^{\circledR}$ markers, and Altoids mints were purchased locally. For dilutions and ESI/DESI solvents, water (Optima grade), methanol (Optima grade), acetonitrile (Optima grade), and chloroform (p.a. grade) were all purchased from Thermo Fisher Scientific (Pittsburgh, PA, USA).

\section{Instrumentation}

The fieldable API instrument used a three-chamber vacuum manifold design with a total volume of approximately $1.3 \mathrm{~L}$. The first vacuum region was evacuated using an Alcatel MDP5011 drag pump backed by a KNF N920 diaphragm pump. This vacuum region communicated with atmosphere via a $10 \mathrm{~cm}$ long, $0.254 \mathrm{~mm}$ I.D. stainless steel capillary (Valco Instrument Co. Inc., Houston, TX, USA) with a flow rate of about 150 $\mathrm{mL} / \mathrm{min}$. Ions exited the capillary and entered the first vacuum region held at about $700 \mathrm{mTorr}$ and passed through a $0.5 \mathrm{~mm}$ I.D. skimmer. Ions exited the skimmer and entered the second vacuum stage, which was held at about 10 mTorr by the drag stage of a Pfeiffer TMH071-015 turbo-drag hybrid pump. The TMH071015 pump was backed by the same KNF N920 diaphragm pump as the Alcatel MDP5011. The second vacuum region contained a transfer octapole driven by a commercial RF octapole supply (Ardara, North Huntingdon, PA, USA). Ions exiting the octapole passed through a 1.5-mm inner diameter conductance limit held at ground potential to enter the third vacuum region. This region was evacuated using the turbo stage of the TMH071-015 to $2 \times 10^{-5}$ Torr, although during operation helium bath gas was leaked in, to a pressure of $5 \times 10^{-4}$ Torr. Upon exiting the conductance limit, ions passed through a three-lens Einzel stack and entered the roughly $1-\mathrm{cm}^{3}$ CIT. Ions were detected using a model 328 conversion dynode/electron multiplier (Detector Technology, Palmer, MA, USA). All instrument components including power supply and vacuum pumps were housed within a single, selfcontained package $45 \mathrm{~cm}$ deep, $45 \mathrm{~cm}$ high, $50 \mathrm{~cm}$ wide, and weighing $45 \mathrm{~kg}$. The size and weight given do not include the DESI or DART sources or the compressed gas cylinders used for operation of the sources.

\section{ESI and DESI}

A commercial Omni Spray source (Prosolia Inc., Indianapolis, IN, USA) was used for both ESI and DESI experiments. For ESI in the positive-ion mode, the electrospray angle was set to about $30^{\circ}$ to the capillary inlet, the spray voltage was set to $+4000 \mathrm{~V}$, and the solvent was $0.1 \%$ formic acid and $50 \% \mathrm{MeOH}$ in water. For DESI analyses, the sample was placed in the front row of an Omni Slide (Prosolia) with the emitter-tosample angle set to $55^{\circ}$ and the emitter placed $1 \mathrm{~mm}$ from the sample. The Omni Slide was positioned directly in front of the capillary inlet such that the sample spot was $1.5 \mathrm{~mm}$ from the inlet. For positive-ion DESI, the solvent composition was $0.1 \%$ formic acid and $75 \%$ acetonitrile in water. For analysis of both RDX (hexahydro-1,3,5-trinitro-1,3,5-triazine) and PETN (pentaerythritol tetranitrate) in negative-ion mode, the solvent was $25 \% \mathrm{CHCl}_{3}$ in acetonitrile. 


\section{DART}

A commercial DART source from IonSense, Inc. (Saugus, MA, USA) was used for all DART experiments. For all DART spectra shown, the DART gas used was helium, at a flow of $2 \mathrm{~L} / \mathrm{min}$ at a temperature of $150^{\circ} \mathrm{C}$. For all spectra shown here (positive-ion mode), the first lens was set to +250 and the second was set to +400 . The DART source was placed $1.5 \mathrm{~cm}$ from the inlet capillary and pointing slightly off-axis to reduce the gas load on the first vacuum stage from the high flow of helium. The sample was held near the edge of the interface between the DART source and the MS inlet for optimal signal levels.

\section{Results and Discussion}

\section{Electrospray Ionization}

Samples of interest in the field are often contained in a liquid matrix or are obtained via extraction [36]. In these events, the optimal signal can often be obtained using ESI because signal levels are typically 10 - to 50 -fold better than those obtained by DART or DESI [34]. A mixture of illicit drugs containing methamphetamine, cocaine, and heroin was analyzed by positive-ion ESI using the prototype API instrument. Protonated molecular ions for each component were observed, as were prominent fragment ions for both methamphetamine and cocaine (Figure 2). For additional confirmation using the CIT, it is possible to isolate each species and perform CID MS/MS on each, enabling rapid confirmation (seconds) in lieu of the minutes of separation required for GC-MS.

\section{DART}

To assess the efficacy of DART for quality control applications, DART was used to generate positive-ion "fingerprint" mass spectra (e.g., no identification of specific components by MS/MS) of different flavors of Altoids brand mints. Flavored Altoids (wintergreen, cinnamon, spearmint, and peppermint) were held near

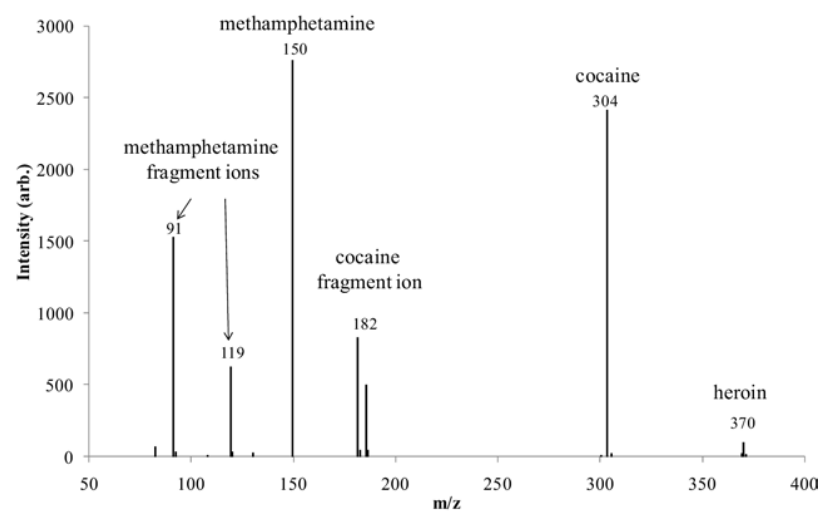

Figure 2. Electrospray ionization of a mixture of methamphetamine, cocaine, and heroin on the prototype API MS instrument.

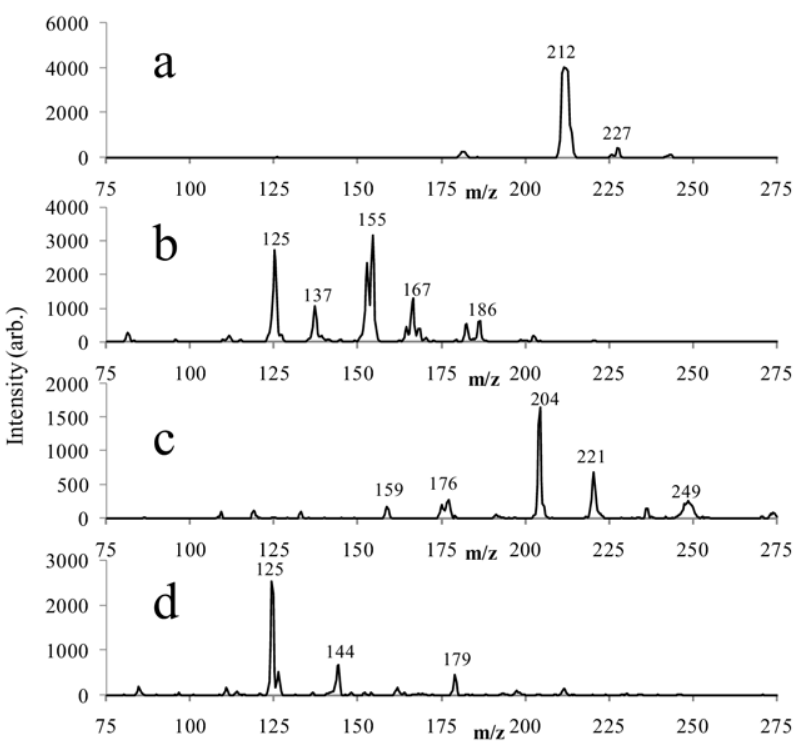

Figure 3. DART MS for differentiation of (a) cinnamon, (b) peppermint, (c) spearmint, and (d) wintergreen Altoids mints.

the interface of the DART source and the MS inlet for sampling. Comparative spectra (Figure 3) allowed differentiation of the flavors by the detection of unique components of each. It should be noted that placement of the sample was straightforward and spectral quality remained stable until the Altoid began to burn $(\sim 4 \mathrm{~min}$ at $150{ }^{\circ} \mathrm{C}$ ). These results exhibit differentiation by fingerprinting and with the addition of MS/MS (not performed in this example), the identity of individual components could be elucidated. In the absence of MS/MS, DART coupled with the relatively low-resolution CIT-MS (compared to the high-resolution time-of-flight MS often coupled with DART in the literature) provided sufficient information for discerning the identity of these related materials.

Previous studies used DART to identify key component(s) of licit and illicit drug tablets [26]. Using the prototype API MS, an ibuprofen tablet was analyzed by holding the tablet in the interface between the DART

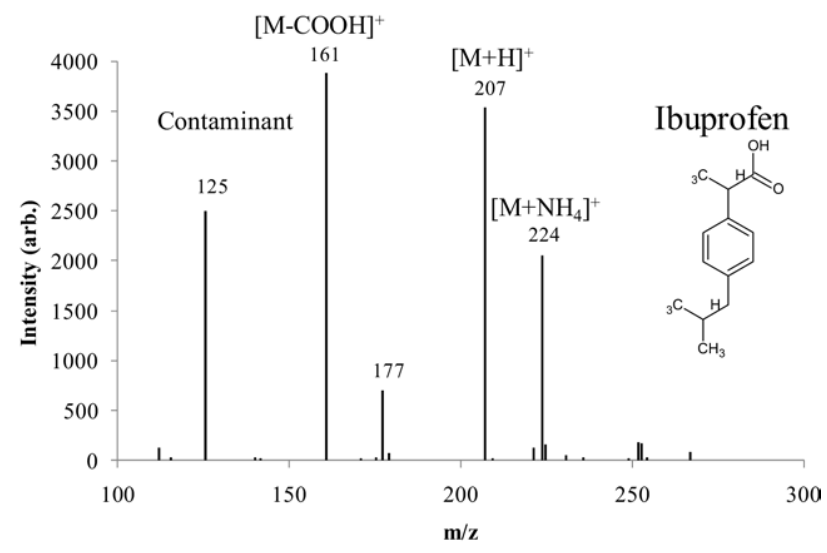

Figure 4. DART MS detection of ibuprofen from the surface of an Advil tablet illustrating the potential for pharmaceutical QA/QC. 


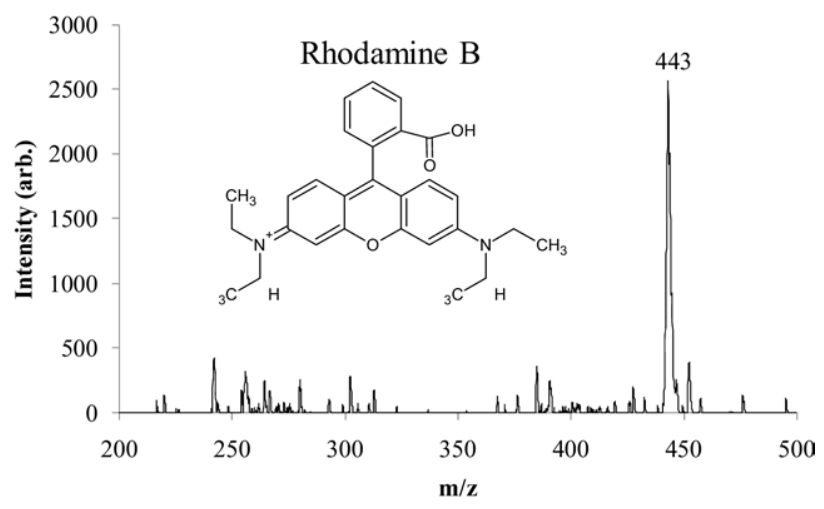

Figure 5. DESI MS detection of rhodamine dye from a spot on an Omni Slide made using a red Sharpie marker.

source and the MS inlet. The most abundant positive ions detected for this experiment corresponded to ibuprofen $[\mathrm{M}+\mathrm{H}]^{+},\left[\mathrm{M}+\mathrm{NH}_{4}\right]^{+}$, and $[\mathrm{M}-\mathrm{COOH}]^{+}$ (Figure 4). This measurement required $<5 \mathrm{~s}$ of analysis time to qualify the content of this tablet, illustrating the utility of DART for fast, qualitative analysis to identify the primary contents of a drug tablet for QA/QC and forensic applications.

\section{$D E S I$}

DESI has been used for the analysis of diverse molecules adsorbed onto materials including ink formulations for forensic and imaging applications [22, 37]. The prototype fieldable API MS was used to detect rhodamine cations generated using DESI from a spot of red
Sharpie ink on laser printer paper. The spectrum (Figure 5) contained a highly intense species at $\mathrm{m} / \mathrm{z} 443$, the mass of rhodamine B [37]. The noise level associated with this experiment was significantly higher than that for the DESI analysis of red ink on an Omni Slide or comparable clean surface as a result of the adsorbent nature of paper and the variety of chemicals used during paper manufacturing. Nonetheless, this example illustrates the rapid detection of a target molecule in a suboptimal matrix such as paper.

Detection of explosives from surfaces has been demonstrated in various DESI-based studies [19, 23, 38-42]. Analysis of explosives in the field is of crucial importance for warfighters, security forces, and crime scene analysts. The prototype fieldable API MS was used to detect the chloride adducts of RDX and PETN anions generated from DESI. Trace amounts of each explosive were placed on an Omni Slide and analyzed by DESI. The lowest levels of each detected in MS-only mode at $>3 \mathrm{~S} / \mathrm{N}$ were $1 \mathrm{ng}$ and $250 \mathrm{pg}$ for RDX and PETN, respectively (Figure 6). The nonlinearities observed with these calibration curves likely appeared because an internal standard was not used and DESI often samples a variable amount of sample loaded onto a surface. To improve $\mathrm{S} / \mathrm{N}$ and confidence of identification of PETN using DESI, CID MS/MS was used for DESI analysis of $1 \mathrm{ng}$ PETN on an Omni Slide (Figure 7). The spectrum showed unfragmented $\left[\mathrm{PETN}+{ }^{37} \mathrm{Cl}\right]$, which was not activated during the resonant excitation and $[\text { PETN }-\mathrm{H}]^{-}$, generated by CID of [PETN + $\left.{ }^{35} \mathrm{Cl}\right]^{-}$. The presence of this characteristic pair of peaks in the spectrum improves confidence in identifications
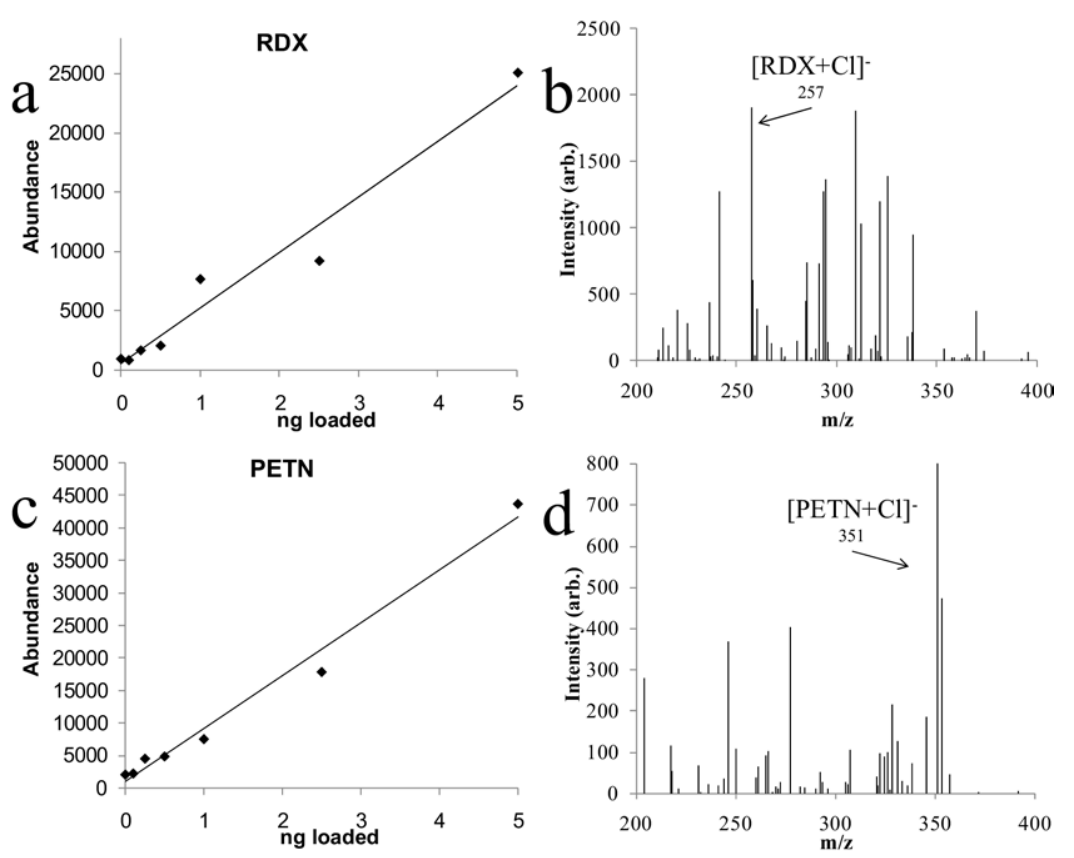

Figure 6. Analysis of explosives using DESI MS on Omni Slide surfaces. (a) Signal versus amount loaded for [RDX $+\mathrm{Cl}^{-}{ }^{-}$. (b) Spectrum collected at $1 \mathrm{ng}$ loaded for RDX showing detection of [RDX + $\mathrm{Cl}^{-}$at $\mathrm{m} / \mathrm{z} 257$. (c) Signal versus amount loaded for $[\mathrm{PETN}+\mathrm{Cl}]^{-}$. (d) Spectrum collected at $500 \mathrm{pg}$ loaded for PETN showing detection of $[\mathrm{PETN}+\mathrm{Cl}]^{-}$at $\mathrm{m} / \mathrm{z} 351$. 


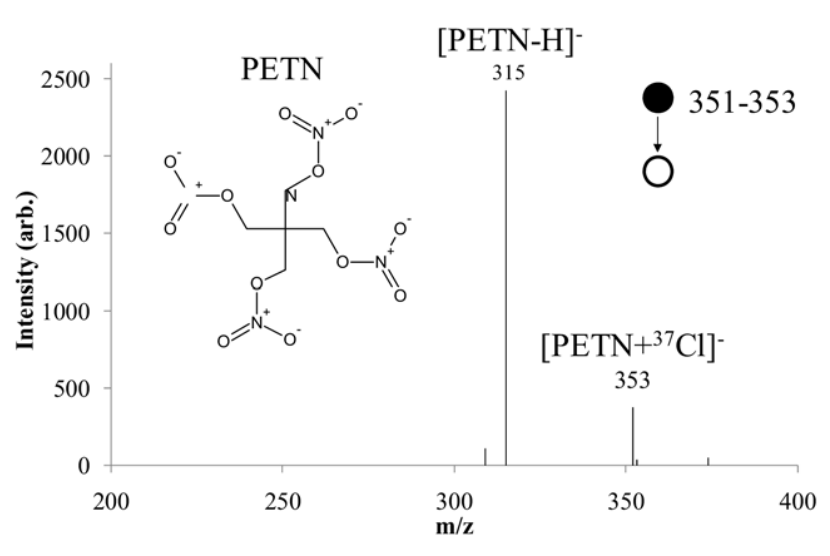

Figure 7. Improved selectivity and S/N using CID MS/MS for PETN identification. Tandem MS spectrum collected from DESI of $1 \mathrm{ng}$ PETN showing loss of the $\mathrm{HCl}$ adduct $(\mathrm{m} / \mathrm{z} 315)$ and unfragmented [PETN $\left.+{ }^{37} \mathrm{Cl}\right]^{-}(\mathrm{m} / \mathrm{z} 353)$, which was not activated by the on-resonance excitation.

and would likely decrease the limits of detection for this application [42]. The confidence associated with true MS/MS (i.e., isolation followed by on-resonance excitation and dissociation) is about that provided with GC-MS (which combines MS information with retention time) [15], but with 100-fold shorter analysis times.

\section{Conclusions and Outlook}

The construction of a prototype API instrument capable of benchtop-quality analyses in the harsh environment of the field opens various doors for the analyst. Wideranging API techniques such as ESI, DESI, DART, and others yield rapid, specific, and accurate information. Further ruggedization of commercially available DESI and DART sources will improve the fieldability of these techniques for advanced field applications, although the current designs are sufficiently rugged for mobile laboratory applications. Utilizing these techniques in mobile laboratories for forensic, environmental, security, defense, and research applications enables the analyst to make informed conclusions, providing direction for subsequent steps to be taken.

The prototype mass spectrometer described here enables improved selectivity and specificity by providing CID MS/MS for identification of both targeted and unanticipated compounds. Interfacing the fieldable API MS with desorption API techniques including DART and DESI extends these techniques beyond the laboratory for point detection in $\mathrm{QA} / \mathrm{QC}$, forensics, crime scene investigation, and security applications. The speed and selectivity of the fieldable API MS instrument provides analysts with the flexibility to perform laboratory-quality analyses in the harsh environment of the field.

\section{Acknowledgments}

The authors thank the National Science Foundation (Grant 0450512) and Air Force Research Laboratory (Contract FA8650-06-
C-5914) for financial support. The authors thank Signature Science, LLC for additional funding. The authors also thank Justin Wiseman of Prosolia and Prof. R. Graham Cooks, Nari Talaty, and Chris Mulligan from Purdue University for assistance with DESI; and Robert Cody of Jeol and Brian Musselman of IonSense for assistance with DART.

\section{References}

1. Kotiaho, T. On-Site Environmental and In-Situ Process Analysis by Mass Spectrometry. J. Mass Spectrom. 1996, 31, 1.

2. Yinon, J. Field Detection and Monitoring of Explosives. Trends Anal. Chem. 2002, 21, 292-301.

3. Wells, J. M.; Grossenbacher, J. W.; Cochran, A. J.; Patterson, G. E.; Rardin, B. D.; Knecht, B. A.; Springston, J. L.; Barket, D. J., Jr. Detection, Identification, and Quantitation of Chemical Weapons and Explosives Using Field-portable GC/MS, Proceedings of the 53rd ASMS Conference on Mass Spectrometry and Allied Topics, San Antonio, TX, June 2005, 5-9.

4. Grossenbacher, J. W.; Wells, J. M.; Patterson, G. E.; Knecht, B. A.; Barket, D. J.; Rardin, B. D. Performance Characterization and Field Testing of a Portable Tandem Mass Spectrometer, Proceedings of the Fourth Workshop on Harsh-Environment Mass Spectrometry (HEMS), St. Petersburg Beach, FL, June 2003, 7-10.

5. Meuzelaar, H. L. C.; Dworzanski, J. P.; Arnold, R. W.; McClennen, W. H.; Wager, D. J. Advances in Field-Portable Mobile GC/MS Instrumentation. Field Anal. Chem. Tech. 2000, 4, 3-13.

6. Santos, F. J.; Galceran, M. T. Modern Developments in Gas Chromatography-Mass Spectrometry-Based Environmental Analysis. J. Chromatogr. A 2003, 1000, 125-151.

7. deHoffmann, E. Tandem Mass. Spectrometry: A Primer. J. Mass Spectrom. 1996, 31, 129-137.

8. Cotter, R. J.; Fancher, C.; Cornish, T. J. Miniaturized Time-of-Flight Mass Spectrometer for Peptide and Oligonucleotide Analysis. J. Mass Spectrom. 1999, 34, 1368-1372.

9. Cornish, T. J.; Bryden, W. A. Miniature Time-of-Flight Mass Spectrometer for a Field-Portable Biodetection System. Johns Hopkins APL Tech. Dig. 1999, 20, 335-342.

10. Keil, A.; Talaty, N.; Janfelt, C.; Noll, R. J.; Gao, L.; Ouyang, Z.; Cooks, R. G. Ambient Mass Spectrometry with a Handheld Mass Spectrometer at High Pressure. Anal. Chem. 2007, 79, 7734-7739.

11. Laughlin, B. C.; Mulligan, C. C.; Cooks, R. G. Atmospheric Pressure Ionization in a Miniature Mass Spectrometer. Anal. Chem. 2005, 77, $2928-2939$.

12. Badman, E. R.; Johnson, R. C.; Plass, W. R.; Cooks, R. G. A Miniature Cylindrical Quadrupole Ion Trap: Simulation and Experiment. Anal. Chem. 1998, 70, 4896-4901.

13. Riter, L. S.; Laughlin, B. C.; Wells, J. M.; Guymon, A. J. A New Miniature Cylindrical Ion Trap Mass Spectrometer for Detection of Chemical Warfare Agents in Air, Pittsburgh Conference (Pittcon), March 2003.

14. Patterson, G. E.; Guymon, A. J.; Riter, L. S.; Everly, M.; Griep-Raming, J.; Laughlin, B. C.; Ouyang, Z.; Cooks, R. G. Miniature Cylindrical Ion Trap Mass Spectrometer. Anal. Chem. 2002, 74, 6145-6153.

15. Committee on Assessment of Security Technologies for Transportation, National Research Council. Opportunities to Improve Airport Passenger Screening with Mass Spectrometry; The National Academies Press: Washington, DC, 2004; pp 1-56.

16. Bereman, M. S.; Nyadong, L.; Fernandez, F. M.; Muddiman, D. C. Direct High-Resolution Peptide and Protein Analysis by Desorption Electrospray Ionization Fourier Transform Ion Cyclotron Resonance Mass Spectrometry. Rapid Commun. Mass Spectrom. 2006, 20, 3409-3411.

17. Chen, H.; Talaty, N. N.; Takats, Z.; Cooks, R. G. Desorption Electrospray Ionization Mass Spectrometry for High-Throughput Analysis of Pharmaceutical Samples in the Ambient Environment. Anal. Chem. 2005, 77, 6915-6927.

18. Cooks, R. G.; Ouyang, Z.; Takats, Z.; Wiseman, J. M. Detection Technologies: Ambient Mass Spectrometry. Science 2006, 311, 1566-1570.

19. Cotte-Rodriguez, I.; Takats, Z.; Talaty, N.; Chen, H.; Cooks, R. G. Desorption Electrospray Ionization of Explosives on Surfaces: Sensitivity and Selectivity Enhancement by Reactive Desorption Electrospray Ionization. Anal. Chem. 2005, 77, 6755-6764.

20. Dong, J.; Rezenom, Y. H.; Murray, K. K. Desorption Electrospray Ionization of Aerosol Particles. Rapid Commun. Mass Spectrom. 2007, 21, 3995-4000.

21. Fernandez, F. M.; Cody, R. B.; Green, M. D.; Hampton, C. Y.; McGready, R.; Sengaloundeth, S.; White, N. J.; Newton, P. N. Characterization of Solid Counterfeit Drug Samples by Desorption Electrospray Ionization and Direct-Analysis in Real-Time Coupled to Time-of-Flight Mass Spectrometry. ChemMedChem 2006, 1, 702-705.

22. Ifa, D. R.; Gumaelius, L. M.; Eberlin, L. S.; Manicke, N. E.; Cooks, R. G. Forensic Analysis of Inks by Imaging Desorption Electrospray Ionization (DESI) Mass Spectrometry. Analyst 2007, 132, 461-467.

23. Justes, D. R.; Talaty, N.; Cotte-Rodriguez, I.; Cooks, R. G. Detection of Explosives on Skin Using Ambient Ionization Mass Spectrometry. Chem Comm 2007, 2142-2144. 
24. Meetani, M. A.; Shin, Y. S.; Zhang, S.; Mayer, R.; Basile, F. Desorption Electrospray Ionization Mass Spectrometry of Intact Bacteria. J. Mass Spectrom. 2007, 42, 1186-1193.

25. Cody, R. B.; Laramee, J. A.; Dupont, H. D. Versatile New Ion Source for the Analysis of Materials in Open Air Under Ambient Conditions. Anal. Chem. 2005, 77, 2297-2302.

26. Williams, J. P. Patel, V. J; Holland, R. Scrivens, J. H. The Use of Recently Described Ionisation Techniques for the Rapid Analysis of Some Common Drugs and Samples of Biological Origin. Rapid Commun. Mass Spectrom. 2006, 20, 1447-1456.

27. Vail, T.; Jones, P. R.; Sparkman, O. D. Rapid and Unambiguous Identification of Melamine in Contaminated Pet Food Based on Mass Spectrometry with Four Degrees of Confirmation. J. Anal. Toxicol. 2007, 31, 304-312.

28. Pierce, C. Y.; Barr, J. R.; Cody, R. B.; Massung, R. F.; Woolfitt, A. R.; Moura, H.; Thompson, H. A.; Fernandez, F. M. Ambient Generation of Fatty Acid Methyl Ester Ions from Bacterial Whole Cells by Direct Analysis in Real Time (DART) Mass Spectrometry. Chem Comm 2007, 807-809.

29. Kpegba, K.; Spadaro, T.; Cody, R. B.; Nesnas, N.; Olson, J. A. Analysis of Self-Assembled Monolayers on Gold Surfaces Using Direct Analysis in Real Time Mass Spectrometry. Anal. Chem. 2007, 79, 5479-5483.

30. Jones, R. W.; Cody, R. B.; McClelland, J. F. Differentiating Writing Inks Using Direct Analysis in Real Time Mass Spectrometry. J. Forensic Sci. 2006, 51, 915-918.

31. Rodriguez-Cruz, S. E. Rapid Analysis of Controlled Substances Using Desorption Electrospray Ionization Mass Spectrometry. Rapid Commun. Mass Spectrom. 2006, 20, 53-60.

32. Cody, R. B., Laramee, J. A. DART: Direct Analysis in Realtime for Drugs, Explosives, Accelerants, Chemical Agents and More; Mass Spectrometry in Forensic Science and Counterterrorism, ASMS Sanibel Conference on Mass Spectrometry, Sanibel Isalnd, FL, February 2005.

33. Takats, Z.; Wiseman, J. M.; Gologan, B.; Cooks, R. G. Mass Spectrometry Sampling Under Ambient Conditions with Desorption Electrospray Ionization. Science 2004, 306, 471-473.
34. D’Agostino, P. A.; Hancock, J. R.; Chenier, C. L.; Jackson Lepage, C. R. Liquid Chromatography Electrospray Tandem Mass Spectrometric and Desorption Electrospray Ionization Tandem Mass Spectrometric Analysis of Chemical Warfare Agents in Office Media Typically Collected during a Forensic Investigation. J. Chromatogr. A 2006, 1110, 86-94.

35. Leuthold, L. A.; Mandscheff, J. F.; Fathi, M.; Giroud, C.; Augsburger, M.; Varesio, E.; Hopfgartner, G. Desorption Electrospray Ionization Mass Spectrometry: Direct Toxicological Screening and Analysis of Illicit Ecstasy Tablets. Rapid Commun. Mass Spectrom. 2006, 20, 103-110.

36. Kientz, C. E. Chromatography and Mass Spectrometry of Chemical Warfare Agents, Toxins and Related Compounds: State of the Art and Future Prospects. J. Chromatogr. A 1998, 814, 1-23.

37. Kertesz, V.; Van Berkel, G. J. Imaging Surfaces by Desorption Electrospray Mass Spectrometry: Issues and Solutions, ASMS Sanibel Conference on Mass Spectrometry, Sanibel Island, FL, January 2007.

38. Chen, H.; Zheng, J.; Zhang, X.; Luo, M.; Wang, Z.; Qiao, X. Surface Desorption Atmospheric Pressure Chemical Ionization Mass Spectrometry for Direct Ambient Sample Analysis without Toxic Chemical Contamination. J. Mass Spectrom. 2007, 42, 1045-1056.

39. Cotte-Rodriguez, I.; Cooks, R. G. Non-Proximate Detection of Explosives and Chemical Warfare Agent Simulants by Desorption Electrospray Ionization Mass Spectrometry. Chem Comm 2006, 2968-2970.

40. Cotte-Rodriguez, I.; Chen, H.; Cooks, R. G., Rapid Trace Detection of Triacetone Triperoxide (TATP) by Complexation Reactions during Desorption Electrospray Ionization. Chem Comm 2006, 953-955.

41. Cotte-Rodriguez, I.; Hernandez-Soto, H.; Chen, H.; Cooks, R. G. In Situ Trace Detection of Peroxide Explosives by Desorption Electrospray Ionization and Desorption Atmospheric Pressure Chemical Ionization. Anal. Chem. 2008, 80, 1512-1519.

42. Takats, Z.; Wiseman, J. M.; Cooks, R. G. Direct, Trace Level Detection of Explosives on Ambient Surfaces by Desorption Electrospray Ionization Mass Spectrometry. Chem Comm 2005, 1950-1952. 